\title{
A VALUABLE VIEW ON EVALUATION OF GENERAL MECHANICAL PERFORMANCES PERTAINING TO Bi-2223 SUPERCONDUCTING CERAMICS WITH VANADIUM ADDITION
}

\author{
Ugur SOYKAN ${ }^{1, *(B)}$, Fidan VELIYEVA ${ }^{2}$ (i) , Gurcan YILDIRIM ${ }^{3}$ \\ ${ }^{1}$ Yenicaga Yasar Celik Vocational High School, Bolu Abant Izzet Baysal University, Bolu-Turkey, 14300 \\ ${ }^{2}$ Department of Chemistry, Bolu Abant Izzet Baysal University, Bolu-Turkey, 14000 \\ ${ }^{3}$ Bolu Abant Izzet Baysal University, Department of Mechanical Engineering, Bolu-Turkey, 14280
}

\begin{abstract}
In this research, our scientific group investigates the effect of vanadium addition in the $\mathrm{Bi}-2223$ superconducting matrix on the general mechanical performance features by the help of experimental microhardness measurements conducted by a small indenter between the well-defined stress loads of $0.245 \mathrm{~N}$ and $2.940 \mathrm{~N}$. Moreover, we determine the key mechanical design parameters including the elastic moduli with the hardness, stiffness coefficients, fracture toughness, yield strength, brittleness index and its opposite behavior (ductility) in the applied test loads given using the experimental data deduced from the microindentation tests. According to the experimental findings, it is oberved that the presence of vanadium content in the Bi2223 crystal structure surpasses seriously the general mechanical performance and related parameters due to the degradation in the quality of grain boundary couplings, crystal structure and basic structural quantities as a consequence of the increment in the structural problems, permanent plastic deformations, crack-producing flaws and dislocations. In other words, the augmentation of vanadium compounds in the $\mathrm{Bi}-2223$ superconducting lattice brings about the considerable enlargement in the responsibility to the static indentation loads. Namely, the sensitive level to the applied loads increases rapidly with the vanadium concentration. We also search the variation of graphs between the Vickers hardness parameters and applied test loads. In this respect, all the materials prepared in this work exhibit the standard ISE (indentation size effect) characteristics but within the decrement trend as the vanadium content level increases. In more detail, the impurity atoms damage harshly the ISE feature of Bi-2223 type-II superconducting ceramics. Additionally, we discuss the change of plateau limit regions coincided with the permeant artificial structural problems in the graphics. The vanadium leads to shorten the applied test load values for the plateau limit regions of Bi-2223 materials, stemmed from the enhancement the general structural problems. To conclude, the vanadium inclusions are ploughed to improve the general mechanical performance features and key mechanical design parameters.
\end{abstract}

Keywords: Vanadium added Bi-2223 material; Microindentation tests; General mechanical performance features; ISE feature

\section{INTRODUCTION}

Phenomenon of superconductivity was first discovered in the year of 1911 for the mercury element by Dutch physicist Heike Kamerlingh Onnes [1]. The phenomenon is shortly summarized as two fundamental features: (I) exactly zero electrical resistivity at a certain lower temperature defined as critical transition temperature and (I) expulsion of magnetic flux fields at certain applied magnetic fields [2]. During more than a century later, the researchers have endeavored to improve their characteristic properties such as the electrical, superconducting, crystal structure, flux pinning, morphological, and especially mechanical performance and characterization so that the materials can be used in much more application fields [3-10]. Among the characteristic features, the mechanical performance is the most important aspect of every application area such as the metallurgical, technological, engineering and industrial fields for the Bi-based superconducting materials [11]. Hence, that the improvement in the mechanical performances has physically occupied several central positions for the application fields of Bi-based superconducting ceramic compounds is not a surprising result. The question is that how we can develop the fundamental mechanical performance and mechanical characterization due to the fact that the ceramic compounds regarding the Bi-containing superconducting parents with their intrinsic brittleness-fault feature and highly susceptible to cracking make some difficulties and faults for the technological, engineering and industrial application fields

*Corresponding Author: ugursoykan@ibu.edu.tr

Received: $30.10 .2020 \quad$ Published: 27.11.2020 
[12]. In this regard, firstly the main purpose is to overcome the brittleness-fault feature. Once the omnipresent flaws (stress raisers and crack initiation sites) and surface cracks in the ceramic compounds can be eliminated in the crystal structure belonging to these kinds of materials, the key mechanical design properties such as the mechanical durability, ductility, hardness, stiffness, toughness, fracture and especially flexural strengths can reach their maximum points due to the diversion or deceleration of crack propagation, crack-producing flaws and dislocation movement. The considerable increment in the mechanical performance enables the mechanical engineers and scientists to pay much more attention to a new question about the application fields including the future heavy-industrial technology, electro-optic and innovative energy infrastructure application fields [13-19]. All in all, the improvement in the mechanical performance of Bi-based superconducting parents is inevitably reality for the appearance of the materials in the future application fields. The reason doubtless is that we search the effect of vanadium addition level up to $\mathrm{x}=0.30$ in the $\mathrm{Bi}-2223$ crystal structure to improve the mechanical characteristic features for the increment in the application fields in the technology, industry and engineering areas. Throughout the current work, the Vickers hardness experiments are exerted at different test loads intervals $0.245 \mathrm{~N}-2.940$ and derived theoretical findings for the first time.

\section{EXPERIMENTAL DETAILS FOR PURE AND VANADIUM ADDED Bi-2223 CERAMICS}

The current work is the continuation of a systematic characterization study of vanadium added Bi2223 ceramic materials. We reported the material production processes such as the chemical purities, standard solid-state reaction method, calcination and sintering conditions (time, temperature, environment atmosphere, palletization load and heating-cooling rates) in the previous paper published [20]. Similarly, one can observe the experimental measurement set-ups and measurement methods in the paper, where the influence of vanadium addition in the Bi-2223 crystal lattice (within the mole ratios of $\mathrm{x}=0,0.01,0.03,0.05,0.07,0.1,0.3)$ on mechanical performance and mechanical identification on the electrical, superconducting, crystal quality, flux pinning and microstructural properties of polycrystalline bulk Bi-2223 superconducting materials is also surveyed in details. Here, we examine the changes of fundamental mechanical performances and mechanical characterization with the vanadium addition (up to $\mathrm{x}=0.30$ in the $\mathrm{Bi}-2223$ crystal structure) with the aid of microhardness measurements (based on the model digital microhardness tester of SHIMADZU HVM2) performed at the room-state temperature in air atmosphere. The indentation test loads interval $0.245 \mathrm{~N}-2.940 \mathrm{~N}$ are applied to the pure and vanadium added Bi-2223 inorganic ceramic compounds for the duration of 10 seconds. The impression tracks of diagonals observed on the material surface are measured by the calibrated microscope. Some measurements are conducted at various locations to gather the optimum microhardness parameters and avoid the hardening problems accumulated on the surface during the Vickers hardness measurements. Besides, we discuss some load-dependent mechanical performance parameters such as Young's modulus (E), fracture toughness (KIC), yield strength (Y) and brittleness index (B) and elastic stiffness coefficient (C11) parameters. Lastly, the mechanical performance curves allow us to define the role of vanadium addition on the mechanical characteristic features founded on the typical indentation size effect (ISE) and reverse indentation size effect (RISE) behavior belonging to all the superconducting materials under the static compression loads [21]. Thereafter, the pure Bi-2223 material will be called as un-substituted or pure compound when the other vanadium added $\mathrm{Bi}-2223$ inorganic solid compounds will be denoted as V-1, V-2, V-3, V-4, V-5 and V-6 materials, respectively.

\section{RESULTS AND DISCUSSION}

\subsection{Determination of Mechanical Performance Founded on Vickers Hardness Measurements}

In the current work, the variations in the mechanical performances and related experimental findings of $\mathrm{Bi}-2223$ superconducting materials as a function of the vanadium addition in the active $\mathrm{Cu}-\mathrm{O}_{2}$ sheets of adjacent layers with the assistant of Vickers microhardness tests performed at the constant applied test load in the range of $0.245 \mathrm{~N}$ and $2.940 \mathrm{~N}$. The experimental measurement results recorded are sensitively discussed in three main parts. In the first extensive part of paper, we focus strictly on why the 
fundamental mechanical performances of pure and vanadium added Bi-2223 inorganic materials improve or suppress with the presence of $\mathrm{V}$ inclusions in the crystal matrix and whether there is a direct relationship between the structural deformations (crystal structure problems, porosity, voids, cracks, disorders, strains, lattice strains, defects, distortions, crack-producing omnipresent flaws, grain alignment distributions and grain boundary coupling problems) and mechanical performances (mechanical durability, ductility, hardness, stiffness, toughness, fracture and especially flexural strengths). In this regard, we examine the differentiation of stress raisers and crack initiation sites affecting seriously the crack propagation and dislocation movement with the vanadium content in the Bi-2223 crystal system. Secondly, the influence of vanadium addition on the mechanical characteristic behaviors defining as ISE and RISE behavior are described scientifically. Thirdly, we express both the load-dependent and load-independent key mechanical design parameters such as Young's modulus, yield strength, fracture toughness, brittleness index and elastic stiffness coefficient by investigating the experimental microhardness curves.

\subsection{Survey of Mechanical Performances for the Bi-2223 Ceramic Materials Prepared}

The mechanical performance curves in Figure 1 show the changes of Vickers hardness values against the applied indentation test loads $(0.245 \mathrm{~N} \leq F \leq 2.940 \mathrm{~N})$ for the virgin and vanadium added Bi-2223 superconducting ceramic compounds. The experimental results displayed graphically in the figure illustrate that the mechanical performance degrade harshly with increasing the vanadium concentration level in the Bi-2223 superconducting core. This is because the structural deformations (known as the crystal structure problems, porosity, voids, cracks, disorders, strains, lattice strains, defects, distortions, crack-producing omnipresent flaws, grain alignment distributions and grain boundary coupling problems in the active adjacent layers of Bi-2223 system) are observed to increase constantly. In this respect, the presence of vanadium addition in the Bi-2223 crystal matrix leads the reduction of both the critical stress value and durable tetragonal phase. In other words, the vanadium particles induce permanently the stress raisers and crack initiation sites acting as crack-producing omnipresent flaws in the crystal system so that the propagation of the crack-initiating flaws, voids, cracks and dislocations accelerates as much as possible to reach the critical propagation speed. This means the (enhancement) reduction of (growth of initial crack) Griffith critical crack length, crack orientation and geometry. To sum up, the regular increment in the vanadium content level in the crystal structure makes the mobility mechanism of dislocations lose control, and the formation and propagation of cracks begin to immediately proceed throughout the grain boundaries. Shortly, the material is much easier broken as compared to before. The long and short of it is that the vanadium addition in the crystal lattice is ploughed to improve the mechanical performance of $\mathrm{Bi}-2223$ superconducting phase.

Numerically, the microhardness $\left(H_{v}\right)$ parameters given in Figure 1 at the different applied test loads are deduced from the following relation:

$$
H_{V}=1854.4\left(\frac{F_{\text {load }}}{d^{2}}\right)
$$

in the formula the abbreviated $F_{\text {load }}$ is directly related to the applied test loads when $d$ ascribes to the mean track length. Every $H_{v}$ value calculated for the pure and vanadium added Bi-2223 ceramic materials is numerically tabulated in Table 1 . According to the $H_{v}$ values in Table 1 , it is easy to understand that the increment in the vanadium impurity level in the Bi-2223 superconducting system harms considerably the microhardness values. For example, at the constant indentation test load of $0.245 \mathrm{~N}$ the $H_{v}$ parameters are obtained to degrade from $4.6129 \mathrm{GPa}$ (for the pure sample) until the global minimum value of $3.6271 \mathrm{GPa}$ (for the V-6 compound). One can easily realize the similar findings for other $H_{v}$ parameters at any applied test loads. The rapid reduction of $H_{v}$ values depending on the enhancement of vanadium additive level points out that new permeant structural deformations induce in the $\mathrm{Bi}-2223$ crystal structure. Moreover, it is another probable result deduced from the numerical values that the $H_{v}$ parameters tend to diminish remarkably with the increment in the applied static test loads up to the maximum level of $2.940 \mathrm{~N}$. This is attributed to the fact that the applied test load much easier damages the V-6 compound in comparison with the other ones due to the presence of 
much more structural deformations. Thus, it is not wrong to confirm that the more vanadium inclusions in the Bi-2223 crystal structure, the less mechanical performance (decrement in the required test load to propagate the cracks and dislocations) and the more mechanical sensitivity to loads we get. On this basis, the bulk V-6 compound can easily be deformed at much lower loads.

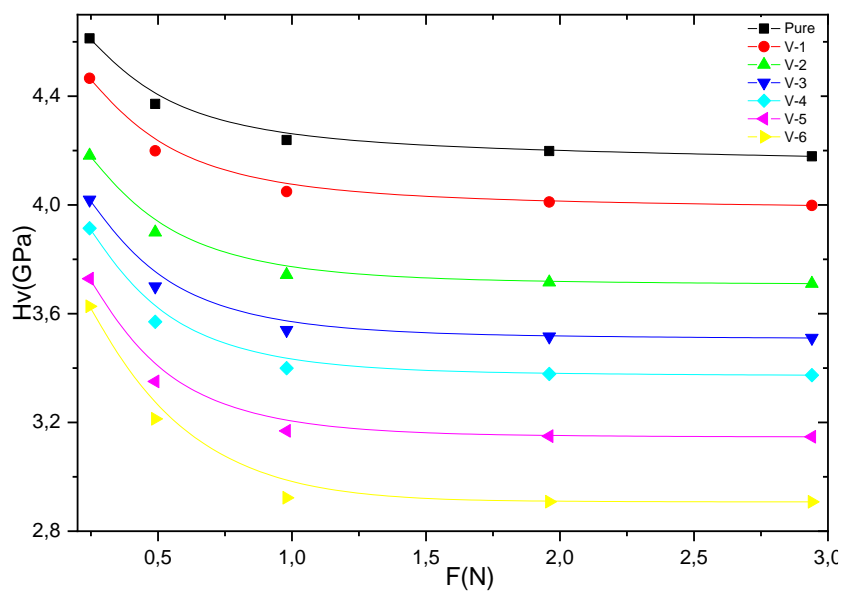

Figure 1. Change of Vickers $H_{v}$ hardness parameters against applied indentation test loads $F$.

Table 1. Load dependent mechanical properties including the elastic modulus (E), yield strength (Y), brittleness index $(B)$, fracture toughness $\left(\mathrm{K}_{\mathrm{IC}}\right)$ and elastic stiffness coefficient $\left(\mathrm{C}_{11}\right)$ parameters for the pure and vanadium added $\mathrm{Bi}-2223$ inorganic ceramic compounds.

\begin{tabular}{|c|c|c|c|c|c|c|c|}
\hline Samples & $F(N)$ & $\mathrm{H}_{v}(\mathrm{GPa})$ & $E(G P a)$ & $Y(G P a)$ & $K_{I C}\left(\mathrm{kPam}^{1 / 2}\right)$ & $C_{11}$ & $B\left(m^{-1 / 2}\right)$ \\
\hline \multirow{5}{*}{ Pure } & 0.2450 & 4.6129 & 378.0894 & 1.5376 & 1.4603 & 14.5196 & 3.1589 \\
\hline & 0.4900 & 4.3716 & 358.3108 & 1.4572 & 1.4216 & 13.2166 & 3.0752 \\
\hline & 0.9800 & 4.2389 & 347.4384 & 1.4130 & 1.3998 & 12.5228 & 3.0282 \\
\hline & 1.9600 & 4.1982 & 344.0984 & 1.3994 & 1.3931 & 12.3129 & 3.0136 \\
\hline & 2.9400 & 4.1787 & 342.5042 & 1.3929 & 1.3899 & 12.2132 & 3.0066 \\
\hline \multirow{5}{*}{ V-1 } & 0.2450 & 4.4659 & 366.0441 & 1.4887 & 1.4894 & 13.7198 & 2.9985 \\
\hline & 0.4900 & 4.1995 & 344.2024 & 1.3998 & 1.4443 & 12.3194 & 2.9077 \\
\hline & 0.9800 & 4.0492 & 331.8833 & 1.3497 & 1.4182 & 11.5582 & 2.8552 \\
\hline & 1.9600 & 4.0112 & 328.7704 & 1.3371 & 1.4115 & 11.3691 & 2.8418 \\
\hline & 2.9400 & 3.9983 & 327.7106 & 1.3328 & 1.4092 & 11.3050 & 2.8372 \\
\hline \multirow{5}{*}{ V-2 } & 0.2450 & 4.1821 & 342.7779 & 1.3940 & 1.4484 & 12.2303 & 2.8874 \\
\hline & 0.4900 & 3.8993 & 319.5995 & 1.2998 & 1.3986 & 10.8199 & 2.7881 \\
\hline & 0.9800 & 3.7432 & 306.8091 & 1.2478 & 1.3703 & 10.0736 & 2.7317 \\
\hline & 1.9600 & 3.7159 & 304.5674 & 1.2386 & 1.3653 & 9.9451 & 2.7217 \\
\hline & 2.9400 & 3.7107 & 304.1387 & 1.2369 & 1.3643 & 9.9206 & 2.7198 \\
\hline \multirow{5}{*}{ V-3 } & 0.2450 & 4.0190 & 329.4105 & 1.3397 & 1.4700 & 11.4079 & 2.7340 \\
\hline & 0.4900 & 3.7001 & 303.2715 & 1.2334 & 1.4105 & 9.8712 & 2.6233 \\
\hline & 0.9800 & 3.5396 & 290.1213 & 1.1799 & 1.3796 & 9.1344 & 2.5658 \\
\hline & 1.9600 & 3.5156 & 288.1484 & 1.1719 & 1.3749 & 9.0259 & 2.5570 \\
\hline & 2.9400 & 3.5108 & 287.7583 & 1.1703 & 1.3739 & 9.0046 & 2.5553 \\
\hline \multirow{5}{*}{$\mathrm{V}-4$} & 0.2450 & 3.9144 & 320.8396 & 1.3048 & 1.4965 & 10.8935 & 2.6157 \\
\hline & 0.4900 & 3.5701 & 292.6204 & 1.1900 & 1.4292 & 9.2725 & 2.4981 \\
\hline & 0.9800 & 3.3996 & 278.6448 & 1.1332 & 1.3946 & 8.5114 & 2.4377 \\
\hline & 1.9600 & 3.3782 & 276.5498 & 1.1247 & 1.3894 & 8.3998 & 2.4285 \\
\hline & 2.9400 & 3.3741 & 276.8924 & 1.1261 & 1.3902 & 8.4180 & 2.4300 \\
\hline \multirow{5}{*}{ V-5 } & 0.2450 & 3.7289 & 305.6362 & 1.2430 & 1.2631 & 10.0063 & 2.9522 \\
\hline & 0.4900 & 3.3510 & 274.6630 & 1.1170 & 1.1974 & 8.2997 & 2.7986 \\
\hline & 0.9800 & 3.1689 & 259.7309 & 1.0563 & 1.1644 & 7.5263 & 2.7215 \\
\hline & 1.9600 & 3.1494 & 258.1342 & 1.0498 & 1.1608 & 7.4455 & 2.7131 \\
\hline & 2.9400 & 3.1471 & 257.9432 & 1.0490 & 1.1604 & 7.4359 & 2.7121 \\
\hline \multirow{5}{*}{ V-6 } & 0.2450 & 3.6271 & 297.2857 & 1.2090 & 1.7190 & 9.5328 & 2.1100 \\
\hline & 0.4900 & 3.2133 & 263.3741 & 1.0711 & 1.6180 & 7.7120 & 1.9860 \\
\hline & 0.9800 & 2.9230 & 239.5752 & 0.9743 & 1.5432 & 6.5341 & 1.8941 \\
\hline & 1.9600 & 2.9084 & 238.3826 & 0.9695 & 1.5393 & 6.4773 & 1.8894 \\
\hline & 2.9400 & 2.9080 & 238.3458 & 0.9693 & 1.5392 & 6.4756 & 1.8893 \\
\hline
\end{tabular}


We also determine the negative effect of vanadium foreign impurities on the mechanical performance by fitting equations between $F_{\text {load }}$ and $H_{v}$ values. One can see the related fitting parameters in Table 2 in detail. It is apparent from the table that the differentiation term of $x^{4}$ is obtained to be in the range from 0.15459 (for the pure sample) to 0.27923 (for the V-6 material). This is in association with the increment in the load-dependence (known as the mechanical sensitivity) of material due to the dramatic enhancement in the number of cracks, voids and dislocations in the crystal lattice. Hence, the propagations of flaws, dislocation movements and crack in the V-6 material highly increase as compared to those of the others. At the same time, it is interesting that the load-dependent Vickers hardness values tend to degrade remarkably with the increment in the applied test load until such a value of about $2 \mathrm{~N}$. (see Figure 1). After the certain load value, the $H_{v}$ values locate in the plateau region (sometimes known as the saturation limit) due to the increased structural deformations in the Bi-2223 crystal system, and any increment in the magnitude of static test load could not change meaningfully the microhardness parameters. Based on the curves in the figure, of the superconducting materials, the bulk V-6 sample reaches to plateau region at rather lowest indentation test loads as a consequence of the decreased critical stress, mechanical strength and durability founded on new induced stress raisers and crack initiation sites. A load value at the saturation region gives the load real (independent or true) microhardness values for a material. In this regard, the pure sample (V-6 sample) has the maximum (minimum) real Vickers values.

Table 2. Fitting parameters are computed for the pure and vanadium added Bi-2223 ceramic compounds.

\begin{tabular}{cc}
\hline Materials & $\begin{array}{c}\text { Fitting relations for the un-added and vanadium added Bi-2223 superconducting } \\
\text { ceramics }\end{array}$ \\
\hline Pure & $\mathrm{y}=0,15459 \mathrm{x}^{4}-1,04385 \mathrm{x}^{3}+2,43715 \mathrm{x}^{2}-2,37175 \mathrm{x}+5,06248$ \\
\hline $\mathrm{V}-1$ & $\mathrm{y}=0,16481 \mathrm{x}^{4}-1,1189 \mathrm{x}^{3}+2,63518 \mathrm{x}^{2}-2,59075 \mathrm{x}+4,95836$ \\
\hline $\mathrm{V}-2$ & $\mathrm{y}=0,17507 \mathrm{x}^{4}-1,19116 \mathrm{x}^{3}+2,81215 \mathrm{x}^{2}-2,7593 \mathrm{x}+4,70620$ \\
\hline $\mathrm{V}-3$ & $\mathrm{y}=0,21253 \mathrm{x}^{4}-1,43379 \mathrm{x}^{3}+3,33796 \mathrm{x}^{2}-3,19951 \mathrm{x}+4,62283$ \\
\hline $\mathrm{V}-4$ & $\mathrm{y}=0,23098 \mathrm{x}^{4}-1,55823 \mathrm{x}^{3}+3,62559 \mathrm{x}^{2}-3,4663 \mathrm{x}+4,56812$ \\
\hline $\mathrm{V}-5$ & $\mathrm{y}=0,25789 \mathrm{x}^{4}-1,73682 \mathrm{x}^{3}+4,02952 \mathrm{x}^{2}-3,83123 \mathrm{x}+4,45032$ \\
\hline $\mathrm{V}-6$ & $\mathrm{y}=0,17923 \mathrm{x}^{4}-1,29913 \mathrm{x}^{3}+3,34284 \mathrm{x}^{2}-3,6394 \mathrm{x}+4,33651$
\end{tabular}

\subsection{Variation of Mechanical Characterization for Bi-2223 Superconducting Phase with Vanadium Inclusions}

As well known, there are two main mechanical characterizations: (I) typical indentation size effect (ISE) and (II) unusual reverse indentation size effect (RISE) behavior. The former feature is in relation to the non-linear differentiation of real microhardness characteristics (inverse dependence to the indentation test load) whereas the latter one ascribes to the direct dependence to the applied load [2224]. It is obvious that all the materials exhibit the typical ISE behavior due to the formation of reversible (elastic) and irreversible (plastic) deformations together in the crystal structure. However, it is to be mentioned here that the $I S E$ characteristic feature decreases regularly as the vanadium addition level increases up to $\mathrm{x}=0.30$, where the bulk V-6 sample presents the global minimum ISE behavior. This is in correspondence to the fact that the vanadium inclusions damage remarkably the quality of crystallinity as a consequence of the rapid increase in the permeant structural deformations in the $\mathrm{Cu}$ $\mathrm{O}_{2}$ consecutively stacked layers. 


\subsection{Mechanical Characteristics of Bulk Superconducting Material}

The curves enable us to determine the load-dependent mechanical performances as regards the yield strength $(\mathrm{Y})$, elastic modulus $(E)$, brittleness index $(B)$, fracture toughness $\left(K_{I C}\right)$ and elastic stiffness coefficient $\left(C_{11}\right)$ parameters by means of equations given below.

$$
\begin{aligned}
& E=81.9635 H_{V} \\
& Y \approx \frac{H_{V}}{3} \\
& K_{I C}=\sqrt{2 E \alpha} \quad(\alpha, \text { surface energy }) \\
& B=\frac{H_{v}}{K_{I C}} \\
& C_{11}=H_{v}^{7 / 4}
\end{aligned}
$$

All the computations performed are numerically tabulated in Table 1. According to table, the substitution mechanism and applied test loads affect strongly the crucial parameters obtained. Namely, every parameter tends to degrade systematically as the substitution level increases up to the maximum value of $x=0.3$. In this respect, the negative effect of vanadium inclusions inserted in the Bi-2223 superconducting system on the load-dependent mechanical performances is obvious. The Young's modulus values are found to be in a range of $378.0894 \mathrm{GPa}$ (for the pure material)- $297.2857 \mathrm{GPa}$ (for the V-6 sample) at the constant applied test load of $0.245 \mathrm{~N}$. Similarly, the value of $378.0894 \mathrm{GPa}$ degrades towards to the value of $342.5042 \mathrm{GPa}$ for the pure material with the increase in the applied indentation test load until the value of $2.490 \mathrm{~N}$. As for the value for the V-6 compound at the load of $2.490 \mathrm{~N}$, the elastic modulus diminishes towards the value of $238.3458 \mathrm{GPa}$. The similar results are obtained for the other parameters. The results show that the V-6 compound requires the smallest energy value to break with the applied load due to the considerable decrement in the strength, stability, stiffness and durability of the material.

\section{CONCLUSIONS}

In the present work, we search the changes of fundamental mechanical performance and mechanical characterization of bulk vanadium added $\mathrm{Bi}-2223$ superconducting materials prepared within the mole-to-mole ratio of $0 \leq x \leq 0.30$. Throughout the survey, we perform the microhardness measurements at various indention test loads between $0.245 \mathrm{~N}$ and $2.940 \mathrm{~N}$. The experimental measurement results are tried to discuss in three main parts. In the first part, we find that the presence of vanadium impurities in the $\mathrm{Bi}-2223$ crystal structure degrades remarkably the mechanical performance due to the augmented permanent crystal structure problems in the crystal matrix. Moreover, we reach an important finding that the vanadium additives inserted induce significantly the stress raisers and crack initiation sites acting as the crack-producing omnipresent flaws. The propagation of the crackinitiating flaws, voids, cracks and dislocations accelerates and reaches the critical propagation speed (the loss of control). Accordingly, the formation and propagation of cracks begin to immediately proceed along with the inter-grain regions (known as the grain boundaries). Thus, the bulk V-6 superconducting sample exhibits least mechanical strength, durability and stiffness to the applied indentation test load because of its brittle nature. In other words, the vanadium added V-6 compound is much easier broken as compared to the other materials. Besides, the same sample reaches to rapidly the plateau region at even the smallest applied test load as a result of new induced stress raisers and 
crack initiation sites in the crystal lattice. As for the second important result inferred from the current work, every material shows the typical $I S E$ feature (but in the decrement trend with the enhancement in the vanadium addition content level), where both the formations of reversible (elastic) and irreversible (plastic) deformations together appear simultaneously in the crystal structure. This is in attribution to the fact that the vanadium foreign particles harm dramatically the quality of crystallinity. Finally, we also describe the crucial load-dependent mechanical properties including the yield strength, elastic modulus, brittleness index, fracture toughness and elastic stiffness coefficient parameters. It is found that the vanadium addition in the $\mathrm{Bi}-2223$ crystal lattice is ploughed to improve the mechanical performance of $\mathrm{Bi}-2223$ superconducting phase.

\section{ACKNOWLEDGEMENTS}

This work was supported by Bolu Abant Izzet Baysal University, Department of Chemistry and Department of Mechanical Engineering.

\section{REFERENCES}

[1] Onnes HK, Further Experiments with Liquid Helium. D. On the Change of Electrical Resistance of Pure Metals at very low Temperatures, etc. V. The Disappearance of the resistance of mercury, Koninklijke Nederlandsche Akademie van Wetenschappen Proceedings, 2011; $14: 113-115$.

[2] Turgay T, Yildirim G. effect of diffusion Annealing Temperature on crack-Initiating Omnipresent Flaws, Void/Crack Propagation and Dislocation Movements Along Ni SurfaceLayered Bi-2223 Crystal Structure. Sakarya University Journal of Science, 2018; 22: 12111220.

[3] Coombs TA. A Finite Element Model of Magnetization of Superconducting Bulks using a Solid-State Flux Pump. IEEE T. Appl. Supercond, 2011; 21: 3581-3586.

[4] Choi KY, Jo IS, Han SC, Han YH, Sung TH, Jung MH, Park GS, Lee SI. High and Uniform Critical Current Density for Large-Size YBa2Cu3O7-y Single Crystals, Curr. Appl. Phys. 2011;11: 1020-1023.

[5] Runde M. Application of high- $\mathrm{T}_{\mathrm{c}}$ Superconductors in Aluminum Electrolysis Plants, IEEE T. Appl. Supercond., 1995; 5: 813-816.

[6] Nagaya S, Hirano N, Naruse M, Watanabe T, Tamada T. Development of a High-Efficiency Conduction Cooling Technology for SMES Coils, IEEE T. Appl. Supercond., 2013; 23: 5602804-5602807.

[7] Xu HH, Cheng L, Yan SB, Yu DJ, Guo LS, Yao X. Recycling Failed Bulk YBCO Superconductors using the NdBCO/YBCO/MgO Film-Seeded Top-Seeded Melt Growth Method. J. Appl. Phys., 2012; 111: 103910.

[8] Batlogg B, Cuprate Superconductors: Science Beyond High T(c), Solid State Commun, 1998; 107: 639-647.

[9] Buckel W, Kleiner R, Superconductivity: Fundamentals and Applications, 2nd ed., Wiley-VCH Verlag, Weinheim, 2004.

[10] Kuczkowski A, Kusz B. High- $\mathrm{T}_{\mathrm{c}}$ Superconductor-Polymer Composites: $\mathrm{YB}_{2} \mathrm{Cu}_{3} \mathrm{O}_{7-\mathrm{x}}-\mathrm{Polyester}$ Polymer and $\mathrm{YBa}_{2} \mathrm{Cu}_{3} \mathrm{O}_{7-\mathrm{x}}-\mathrm{Teflon}$, Synth. Met. 1998; 94: 145-148. 
[11] Zalaoglu Y, Bekiroglu E, Dogruer M, Yildirim G, Ozturk O, Terzioglu C. Comparative Study on Mechanical Properties of Undoped and Ce-doped Bi-2212 Superconductors. J. Mater. Sci: Mater. El., 2013; 24: 2339-2345.

[12] Zalaoglu Y, Karaboga F, Terzioglu C, Yildirim G. Improvement of Mechanical Performances and Characteristics of Bulk Bi-2212 Materials Exposed to Au Diffusion and Stabilization of Durable Tetragonal Phase by Au, Ceram. Int., 2017; 43: 6836-6844.

[13] Koyama K, Kanno S, Noguchi S. Electrical, Magnetic and superconducting Properties of the Quenched $\mathrm{Bi}_{2} \mathrm{Sr}_{2} \mathrm{Ca}_{1-\mathrm{X}} \mathrm{Nd}_{\mathrm{X}} \mathrm{Cu}_{2} \mathrm{O}_{8+\mathrm{y}}$ system, Jpn. J. Appl. Phys., 1990; 29: L53-L56.

[14] Egi T, Wen JG, Kuroda K, Unoki H, Koshizuka N, High-current Density of $\mathrm{Nd}(\mathrm{Ba}, \mathrm{Nd})_{2} \mathrm{Cu}_{3} \mathrm{O}_{7-\mathrm{X}}$ Single-crystal, Appl. Phys. Lett., 1995; 67: 2406-2408.

[15] Jin S, Tiefel TH, Sherwood RC, Davis ME, Van Dover RB, Kammlott GB, Fasrnacht RA, Keith HD. High Critical Currents in Y-Ba-Cu-O Superconductors, Appl. Phys. Lett., 1988; 52: 20742076.

[16] Zhou L, Zhang P, Ji P, Wang K, Wu X. The properties of YBCO Superconductors Prepared by A New Approach-The Powder Melting Process, Supercond. Sci. Technol., 1990, 3: 490-492.

[17] Salama K, Selymanickam V, Gao L, Sun K. High-Current Density in Bulk $\mathrm{YBa}_{2} \mathrm{Cu}_{3} \mathrm{O}_{\mathrm{x}}$ Superconductor, Appl. Phys. Lett., 1989; 54: 2352-2354.

[18] Miao H, Meinesz M, Czabai B, Parrell J, Hong S. Microstructure and $\mathrm{J}_{\mathrm{c}}$ Improvements in Multifilamentary Bi-2212/Ag Wires for High Field Magnet Applications, AIP Conference Proceedings, 2008; 986: 423-430.

[19] Yildirim G, Beginning Point Of Metal To Insulator Transition For Bi-2223 Superconducting Matrix Doped With Eu Nanoparticles, J. Alloy. Compd., 2013; 578: 526-535.

[20] Zalaoglu Y. Determination of Solubility Characteristic of (Bi, Gd) Substitution in Bi-2223 Inorganic Compounds, Sakarya University Journal of Science, 2018; 22: 1221-1233.

[21] Elmustafa AA, Stone DS. Nanoindentation and the Indentation Size Effect: Kinetics of Deformation and strain gradient Plasticity, J. Mech. Phys. Solid., 2003; 51: 357.

[22] Poehl F, Huth S, Theisen W. Detection of the İndentation-Size-Effect (ISE) and Surface Hardening by Analysis of the Loading Curvature C., Int. J. Solids Struct., 2016; 84: 160-166.

[23] Pasare MM, Petrescu MI. A Theoretical Model for the true hardness Determination of Ni-P/SiC Electroplated Composites, Mater. Plast., 2008; 45: 87-90.

[24] Al-Rub RKA. Prediction of Micro and Nanoindentation Size Effect From Conical or Pyramidal Indentation. Mech. Mater., 2007; 39: 787-802. 